\title{
Progress in the Research on the Antiviral Drug Remdesivir
}

\author{
Ziyue Huang ${ }^{1(\mathbb{D})}$, Lan $\mathrm{Su}^{2}$ (D), Yunchun $\mathrm{Li}^{3}{ }^{3}{ }^{*} \mathbb{C}$ \\ Shanghai Jiao Tong University School of Medicine, Shanghai 200025, China \\ Department of Clinical Pharmacy, West China Hospital, Sichuan University, Chengdu 610041, China \\ Department of Nuclear Medicine, West China Hospital, Sichuan University, Chengdu 610041, China \\ Correspondence: ycliwc@163.com;
}

Scopus Author ID 36062902400

Received: 10.03.2020; Revised: 25.05.2020; Accepted: 28.05.2020; Published: 7.06.2020

\begin{abstract}
Novel coronavirus disease (COVID-19) broke out in Wuhan, China, and has spread throughout the country, affecting many countries around the world. Because there is no etiological treatment for COVID-19, it is very urgent to find effective antiviral drugs to control the rapid spread of this disease. Remdesivir is a nucleotide prodrug that has broad-spectrum antiviral activity. It can interfere with viral RNA synthesis and play an antiviral role. This article reviews the pharmacological effects of remdesivir, some animal trials, in vitro and in vivo experiments, and clinical trials.
\end{abstract}

Keywords: novel coronavirus; remdesivir; antiviral drugs; animal experiments; clinical trials.

(C) 2020 by the authors. This article is an open-access article distributed under the terms and conditions of the Creative Commons Attribution (CC BY) license (https://creativecommons.org/licenses/by/4.0/).

\section{Introduction}

Novel coronavirus disease (COVID-19) broke out in Wuhan, China, and has spread rapidly throughout the country and the world. As of 24:00 on February 17, 2020, there were 72,436 confirmed cases nationwide with a death toll of 1,868. COVID-19 has proven to be highly infectious through human-to-human transmission, causing many severe cases and high mortality rates. The World Health Organization has declared this epidemic as an international public health emergency[1]. The number of confirmed cases and deaths continues to increase, but we currently do not have any etiological treatment for COVID-19; some antiviral drugs and Chinese medicines have been used in the clinical treatment of COVID-19, but their effect for this disease is still not clear. So, it is urgent for researchers to actively find targeted therapeutic drugs to control the COVID-19 epidemic.

At present, scientists are committed to the research and development of new drugs and vaccines with high efficiency and low toxicity. At the same time, scientists are also continuously screening suitable drugs among marketed drugs. Potential drugs currently screened include nucleoside inhibitors acting on key enzymes for viral replication, such as the guanine nucleoside analog ribavirin and the adenine nucleoside analog remdesivir; protease inhibitors, such as lopinavir and ritonavir; antagonists of angiotensin-converting enzyme 2 receptors acting on host cells; and polypeptides and monoclonal antibodies acting on dendritic proteins of viruses [2]. At the same time, chloroquine, interferon, and other drugs that have been marketed have also shown a certain effect in the therapeutic treatment of novel coronavirus disease. Many clinical trials for COVID-19 have been launched, including two high-profile randomized controlled phase III clinical trials using remdesivir in 760 cases in Wuhan Jinyintan Hospital. This article will review the pharmacological effects, animal trials, in vitro and in vivo experiments, and clinical trials of remdesivir. 


\section{Pharmacological Effect}

Remdesivir is an antiviral drug that is still in development; it has passed phase I and II clinical trials but has not yet been marketed. It is an antiviral nucleoside prodrug that is metabolized into pharmacologically active triphosphates in the body, and it competes with ATP to integrate into the nascent viral RNA chain [3]. By inhibiting viral RNA-derived RNA polymerase (RdRp), remdesivir interferes with the synthesis of RNA and thus plays an antiviral role.

Remdesivir was designed to treat the Ebola virus. In subsequent in vitro and animal experiments, remdesivir was found to have a certain inhibitory effect on Middle East respiratory syndrome coronavirus (MERS-CoV), severe acute respiratory syndrome coronavirus (SARS-CoV), Ebola Coronavirus, and many other coronaviruses. Remdesivir is a broad-spectrum anti-coronavirus drug.

\section{Anti-Ebola Virus}

Ebola virus is an enveloped, single-stranded, negative-sense, non-segmented RNA virus that belongs to the family of filoviruses and is transmitted through patients' blood, saliva, sweat, and secretions. The extremely high mortality rate of the Ebola virus has scared the world. Gilead has been developing antiviral drugs for a long time. In 2010, it began to study antiEbola drugs.

In 2016, Warren et al. reported the in vivo antiviral effect of the adenosine analog remdesivir (GS-5734) on the Ebola virus in nonhuman primates [4]. They examined the pharmacokinetics 、 distribution and metabolism of remdesivir. After administering remdesivir to the animal, it showed that remdesivir could efficiently convert to active triphosphates and distribute to multiple organs throughout the body, including eye, testes, brain. And in the brain, it could be detectable $168 \mathrm{~h}$ post-dose. These showed that once-daily dosing of remdesivir was enough to keep the triphosphates level and make sure the places that viruses may exist can have drug distribution. The survival rate of the animals which were injected remdesiver( $3 \mathrm{mg} \cdot \mathrm{kg}-1)$ intramuscularly after got infected with the Ebola virus within $2 \sim 4$ days was about $50 \%$. No animal survived in the placebo group.

Jacobs et al, were the first to use remdesivir in the treatment for patients with Ebola virus infection[20]. This was a 39-year-old patient with meningoencephalitis caused by the late Ebola virus relapse. At the beginning of the treatment, a monoclonal antibody MIL77 was used. But this caused a strong allergic reaction, which necessitated a change in the treatment. Compassionate use of remdesivir was given to the patient on the seventh day. The dose of remdesivir for the first three days was $150 \mathrm{mg}$. Later it increased to $225 \mathrm{mg}$ and lasted for 11days. During these 14 days of treatment, the level of Ebola virus gradually decreased and eventually could not be detected. However, the untreated Ebola virus meningoencephalitis's natural history was unknown. So it was not sure whether the change in the clinical course of the disease was due to antiviral treatment or not.

Scientists also carried out corresponding clinical trials to test remdesivir's anti-Ebola effect. In the phase I clinical trial, the patients received an intravenous infusion of remdesivir, and the remdesivir showed fairly good drug safety and good pharmacokinetic parameters; no adverse effects were seen from $150 \mathrm{mg}$ to $225 \mathrm{mg}$ in the increased dose. Ebola virus disappeared from blood and cerebrospinal fluid after 14 days of treatment in adults and 
infants[5]. In phase II clinical trial, a randomized controlled trial was carried out[21]. The patients with Ebola virus infection were randomly divided into 4 groups according to the ratio of 1:1:1:1. These four groups were treated with triple monoclonal antibody ZMapp, remdesivir, single monoclonal antibody MAb114, and triple monoclonal antibody REGN-EB3, respectively. However, after the interim analysis of the data, the uses of remdesivir and ZMapp in this trial were recommended to be terminated. There were two reasons for that: firstly, the mortality in remdesivir group exceeded $50 \%$, while the others were only around 30\%(MAb114, REGN-EB3). Secondly, according to the analysis of the time to the first negative result, the estimated median time in the remdesivir group was more than 28 days, and that was the longest one compared to Mab114 group(16days), REGN-EB3 group(15days) and ZMapp group(27 days).

The clinical trial proved that remdesivir was not an effective anti-Ebola virus drug for the human being. However, its good antiviral effect in cell and animal experiments makes scientists want to keep further research on it. Scientists speculated that remdesivir might be more effective in treating other viral infections. So, some researches were carried out to verify this speculation.

\section{Anti-Coronavirus}

Coronaviruses (covs) are important pathogens of humans and vertebrates. They can infect humans and a variety of wild animals. There are six types of covs that are known can infect humans, including MERS-CoV and SARS-CoV, which can enter the body through its $\mathrm{CoV}$ receptors and replicate in human respiratory epithelial cells, [6] causing severe respiratory diseases. Remdesivir has anti-SARS-CoV and anti-MERS-CoV activity.

\subsection{Anti-SARS-CoV and anti-MERS-CoV activity.}

A 2017 study by Denison and Baric's team demonstrated that remdesivir could inhibit both epidemic and zoonotic coronaviruses. In a mouse model of SARS-CoV, prophylactic, and early therapeutic administration of remdesivir significantly reduced viral load in the lungs and improved clinical signs of the respiratory system. SARS-CoV and MERS-CoV are both coronaviruses and have certain similarities. These research data provided substantial evidence that remdesivir may inhibit MERS-CoV and some other human epidemic coronaviruses and prevent SARS-CoV and MERS-CoV replication in human airway epithelial cells [7]. This team went on to verify the previous hypothesis and continued the experiments. In 2020, the team compared the effects of multiple antiviral drugs on a mouse model of MERS-CoV, and remdesivir showed effectiveness in inhibiting the replication of MERS-CoV.

The median effect concentration (EC50) was $0.09 \mu \mathrm{mol} \cdot \mathrm{L}-1$, no observable cytotoxicity was found at concentrations up to $10 \mu \mathrm{mol} \cdot \mathrm{L}-1$, and the selectivity index (SI $=$ EC50/CC50) was > 100. The EC50 of lopinavir and ritonavir was $11.6 \mu \mathrm{mol} \cdot \mathrm{L}-1$ and $24.9 \mu \mathrm{mol} \cdot \mathrm{L}-1$, confirming the previous hypothesis that remdesivir has the potential to treat MERS-CoV infection [8]. It is worth noting that in this study, by comparing multiple antiviral drugs, it was proven that remdesivir not only has the effect of preventing MERS-CoV infection but is also the only treatment that can significantly reduce the lungs' pathological symptoms under MERS-CoV infection.

In 2020, Emmie de Wit et al. verified the prophylactic and therapeutic effects of remdesivir on MERS-CoV in a nonprimate (rhesus macaque) model. This animal trial was 
divided into 3 groups: a group-administered drugs 24 hours before infection, a groupadministered drugs 12 hours after infection, and a control group. Treatment was performed once a day until the 6th day after vaccination. The trial results showed that remdesivir had obvious therapeutic and prophylactic effects and could reduce clinical symptoms (pulmonary lesions) and virus replication [9].

\subsection{Anti-novel coronavirus activity.}

The novel coronavirus (2019-nCoV) is an enveloped, single-stranded, positive-sense RNA virus. The 2019-nCoV genome encodes nonstructural, structural, and accessory proteins. According to a preliminary analysis of its genome, the catalytic sites of the four enzymes in 2019-nCoV are highly conserved and highly similar to the sequences of SARS and MERS. Among them, the RdRP protein has more than 90\% similarity [10]. In addition, protein structure analysis suggests that the key drug-binding pockets of 2019-nCoV, SARS-CoV, and MERS-CoV viral enzymes are conserved. Therefore, the treatment of 2019-nCoV with SARS and MERS inhibitors is reasonable [2]. At the same time, nucleoside analogs usually target viral replication, especially viral DNA or RNA polymerase. However, the unique CoV proofreading 3'-5'exoribonuclease (ExoN) will affect the nucleoside analog's ability to interfere with viral RNA synthesis [6]. Fortunately, remdesivir is not be excised by nsp14ExoN and has strong in vitro antiviral activity [11].

Because previous studies showed that remdesivir has an inhibitory effect on SARS$\mathrm{CoV}$ and MERS-CoV and has strong antiviral activity in vitro, the possibility of using remdesivir as a treatment plan has also been mentioned many times in the potential treatment plans for COVID-19.

Liu W S et al. suggested the use of remdesivir as a potential inhibitor against 2019nCoV [12]. Alimuddin Zumla et al. pointed out that host-directed therapy may be an option to reduce the mortality of COVID-19, and they also mentioned combination therapy with antiviral drugs such as remdesivir [13]. Wang Fusheng et al. mentioned the use of and research on remdesivir in this epidemic when thinking about how to control COVID-19 [14].

In February 2020, Wang Manli et al. tested the effectiveness of existing antiviral drugs in treating COVID-19 infection through in vitro cell tests and found that chloroquine and remdesivir were very effective in controlling COVID-19 infection in vitro; the half-maximal inhibitory concentration (IC50) for remdesivir for the treatment of novel coronavirus infection was $0.77 \mu \mathrm{mol} \cdot \mathrm{L}-1$, and the authors recommended continuing the evaluation of these drugs in patients [15].

In January 2020, Michelle L. Holshue et al. first reported the use of remdesivir in the treatment for COVID-19 in a patient in the United States. The patient's condition had not been effectively improved and even worsened 6 days after admission. The hospital pursued compassionate use of the investigational antiviral therapy on the seventh day and gave the patient an intravenous injection of remdesivir. The patient's clinical condition improved the next day after the medication was administered, and the previous bilateral lower lobe rales disappeared. Supplemental oxygen was discontinued, and the oxygen saturation values reached $94 \%$ to $96 \%$. As of January 30, 2020, all symptoms except fever and cough have been alleviated, and the degree of a cough has been reduced [16]. The successful application of remdesivir, in this case, has attracted global attention, but further clinical trials are still needed to prove the safety and efficacy of remdesivir in the treatment of COVID-19. 
The patient who was given compassionate medicine in the United States was in severe condition and was the only patient to receive remdesivir in the treatment of COVID-19. However, most patients in China had mild and moderate pneumonia. Severe patients are very different from mild and moderate patients in pathology, and the efficacy of the same drug may also be different [17]. Whether researchers can learn from this and use remdesivir to treat severely ill patients will require more supportive clinical data. In February 2020, a phase III clinical trial of remdesivir for COVID-19 was initiated in China. A total of 760 patients with mild, moderate, and severe COVID-19 respiratory disease were recruited to participate in a randomized, double-blind, placebo-controlled, multicenter study to evaluate the safety and efficacy of remdesivir in hospitalized adult patients with mild, moderate, and severe COVID19 respiratory disease $[18,19]$. Patients were divided into a remdesivir group and a control group: the experimental group was given a $200 \mathrm{mg}$ loading dose of remdesivir on the first day, and then a $100 \mathrm{mg}$ intravenous maintenance dose was administered once a day for 9 days; the control group was given the corresponding placebo.

\section{Conclusions}

Remdesivir in vitro and animal experiments have proven its effectiveness and safety in inhibiting SARS-CoV and MERS-CoV. The novel coronavirus has gene sequence similarity with SARS-CoV and MERS-CoV. Remdesivir treatment of novel coronavirus is biologically feasible, and the first case in the United States in which remdesivir was successfully used for rapid treatment of COVID-19 further gave scientists the motivation and confidence to explore this treatment option further. We look forward to the results of phase III clinical trial of remdesivir in China, and we also look forward to other good news from other clinical trials and vaccine development.

\section{Funding}

This research was funded by the Science \& Technology Department of Sichuan Province, grant number 2018 SZ0234.

\section{Acknowledgments}

It was sponsored by Science \& Technology Department of Sichuan Province (number: 2018SZ0234).

\section{Conflicts of Interest}

The authors declare no conflict of interest. The funders had no role in the design of the study; in the collection, analyses, or interpretation of data; in the writing of the manuscript, or in the decision to publish the results.

\section{References}

1. National Health Commission of the People's Republic of China. Available online: http://www.nhc.gov.cn/xcs/xxgzbd/gzbd_index.shtml

2. Li, G.; De Clercq, E. Therapeutic options for the 2019 novel coronavirus (2019-nCoV). Nature review 2020, 19, https://www.nature.com/articles/d41573-020-00016-0.

3. Tchesnokov, E.P.; Feng, J.Y.; Porter, D.P.; Gotte, M. Mechanism of inhibition of Ebola virus RNAdependent RNA polymerase by remdesivir. Viruses 2019, 11, 326, https://doi.org/10.3390/v11040326.

4. Warren, T.K.; Jordan, R.; Lo, M.K.; Ray, A.S.; Mackman, R.L.; Soloveva, V.; Siegel, D.; Perron, M.; 
Bannister, R.; Hui, H.C.; Larson, N.; Strickley, R.; Wells, J.; Stuthman, K.S.; Van Tongeren, S.A.; Garza, N.L.; Donnelly, G.; Shurtleff, A.C.; Retterer, C.J.; Gharaibeh, D.; Zamani, R.; Kenny, T.; Eaton, B.P.; Grimes, E.; Welch, L.S.; Gomba, L.; Wilhelmsen, C.L.; Nichols, D.K.; Nuss, J.E.; Nagle, E.R.; Kugelman, J.R.; Palacios, G.; Doerffler, E.; Neville, S.; Carra, E.; Clarke, M.O.; Zhang, L.; Lew, W.; Ross, B.; Wang, Q.; Chun, K.; Wolfe, L.; Babusis, D.; Park, Y.; Stray, K.M.; Trancheva, I.; Feng, J.Y.; Barauskas, O.; Xu, Y.; Wong, P.; Braun, M.R.; Flint, M.; McMullan, L.K.;Chen, S.S.; Fearns, R.; Swaminathan, S.; Mayers, D.L.; Spiropoulou, C.F.; Lee, W.A.; Nichol, S.T.; Cihlar, T.; Bavari, S. Therapeutic efficacy of the small molecule GS-5734 against Ebola virus in rhesus monkeys. Nature 2016, 531, 381-385, https://doi.org/10.1038/nature17180.

5. Guo, Z.R. Remdesivir:from Compassionate Use to Phase Three Clinical Trial.[J/OL]. Acta Pharmaceutica Sinica. 2020, 1-6,http://doi.org/10.16438/j.0513-4870.2020-0103.

6. Agostini, M.; Andres, E.; Sims, A.; Graham, R.; Sheahan, T.; Lu, X.; Smith, E.; Case, J.; Feng, J.; Jordan, R.; Ray, A.S.; Chihlar, T.; Siegel, D.; Mackman, R.L.; Clarke, M.O.; Baric, R.; Denison, M. Coronavirus Susceptibility to the Antiviral Remdesivir (GS-5734) Is Mediated by the Viral Polymerase and the Proofreading Exoribonuclease. mBio 2018, 9, e00221-00218, https://doi.org/10.1128/mBio.00221-18.

7. Sheahan, T.P.; Sims, A.C.; Graham, R.L.; Menachery, V.D.; Gralinski, L.E.; Case, J.B.; Leist, S.R.; Pyrc, K.; Feng, J.Y.; Trantcheva, I.; Bannister, R.; Park, Y.; Babusis, D.; Clarke, M.O.; Mackman, R.L.; Spahn, J.E.; Palmiotti, C.A.; Siegel, D.; Ray, A.S.; Cihlar, T.; Jordan, R.; Denison, M.R.; Baric, R.S. Broad-spectrum antiviral GS-5734 inhibits both epidemic and zoonotic coronaviruses. Science translational medicine 2017, 9, https://doi.org/10.1126/scitranslmed.aal3653.

8. Sheahan, T.P.; Sims, A.C.; Leist, S.R.; Schäfer, A.; Won, J.; Brown, A.J.; Montgomery, S.A.; Hogg, A.; Babusis, D.; Clarke, M.O.; Spahn, J.E.; Bauer, L.; Sellers, S.; Porter, D.; Feng, J.Y.; Cihlar, T.; Jordan, R.; Denison, M.R.; Baric, R.S. Comparative therapeutic efficacy of remdesivir and combination lopinavir, ritonavir, and interferon beta against MERS-CoV. Nature Communications 2020, 11, 222, https://doi.org/10.1038/s41467-019-13940-6.

9. Wit, E.; Feldmann, F.; Cronin, J.; Jordan, R.; Okumura, A.; Thomas, T.; Scott, D.; Cihlar, T.; Feldmann, H. Prophylactic and therapeutic remdesivir (GS-5734) treatment in the rhesus macaque model of MERS-CoV infection. Proceedings of the National Academy of Sciences 2020, https://doi.org/10.1073/pnas.1922083117.

10. Xu, X.T.; Chen, P.; Wang, J.F.; Feng, J.N.; Zhou, H.; Li, X.; Zhong, W.; Hao, P. Evolution of the novel coronavirus from the ongoing Wuhan outbreak and modeling of its spike protein for risk of human transmission[DB/OL]. Sci China Life Sci 2020, http://dx.doi.org/10.1007/s11427-020-1637-5.

11. Song, G.; Cheng, M.Q.; Wei, X.W. Novel Coronavirus (2019-nCoV) Therapeutic Drugs in Vivo and in Vitro Research and Drug Development Progress[J/OL]. Chinese Journal of Virology 2020, 1-6, https://doi.org/10.13242/j.cnki.bingduxuebao.003646.

12. Morse, J.S.; Lalonde, T.; Xu, S.; Liu, W.S. Learning from the past: Possible urgent prevention and treatment options for severe acute respiratory infections caused by 2019-nCoV. ChemRxiv 2020, https://doi.org/10.26434/chemrxiv.11728983.v1.

13. Zumla, A.; Hui, D.S.; Azhar, E.I.; Memish, Z.A.; Maeurer, M. Reducing mortality from 2019-nCoV: hostdirected therapies should be an option. Lancet 2020, 395, e35-e36, https://doi.org/10.1016/S01406736(20)30305-6.

14. Wang, F.S.; Zhang, C. What to do next to control the 2019-nCoV epidemic? The Lancet 2020, 395, 391-393, https://doi.org/10.1016/S0140-6736(20)30300-7.

15. Wang, M.; Cao, R.; Zhang, L.; Yang, X.; Liu, J.; Xu, M.; Shi, Z.; Hu, Z.; Zhong, W.; Xiao, G. Remdesivir and chloroquine effectively inhibit the recently emerged novel coronavirus (2019-nCoV) in vitro. Cell Res. 2020, 30, 269-271, https://doi.org/10.1038/s41422-020-0282-0.

16. Holshue, M.L.; DeBolt, C.; Lindquist, S.; Lofy, K.H.; Wiesman, J.; Bruce, H.; Spitters, C.; Ericson, K.; Wilkerson, S.; Tural, A.; Diaz, G.; Cohn, A.; Fox, L.; Patel, A.; Gerber, S.I.; Kim, L.; Tong, S.; Lu, X.; Lindstrom, S.; Pallansch, M.A.; Weldon, W.C.; Biggs, H.M.; Uyeki, T.M.; Pillai, S.K. Washington State 2019-nCoV Case Investigation Team. First Case of 2019 Novel Coronavirus in the United States. The New England journal of medicine 2020, 382, 929-936, https://doi.org/10.1056/NEJMoa2001191.

17. Liu, Q.Y.; Wang, X.L. Targeted Drug Research Strategy for Novel Coronavirus (2019-nCoV). Acta Pharmaceutica Sinica 2020, 1-17, http://doi.org/10.16438/j.0513-4870.2020-0106.

18. A phase 3 randomized, double-blind, placebo-controlled multicenter study to evaluate the efficacy and safety of remdesivir in hospitalized adult patients with mild and moderate 2019-nCoV respiratory disease[ED/OL]. ClinicalTrials.gov Identifier: NCT04252664. https://www.clinicaltrials.gov.

19. A phase 3 randomized, double-blind, placebo-controlled, multicenter study to evaluate the efficacy and safety of remdesivir in hospitalized adult patients with severe 2019-nCoV respiratory disease[ED/OL]. ClinicalTrials.gov Identifier: NCT04257656. https://www.clinicaltrials.gov.

20. Jacobs M, Rodger A, Bell DJ, et al. Late Ebola virus relapse causing meningoencephalitis: a case report. Lancet 2016, http://doi.org/10.1016/S0140-6736(16)30386-5.

21. Nakkazi E. Randomised controlled trial begins for Ebola therapeutics. Lancet 2018, http://doi.org/10.1016/S0140-6736(18)33011-3. 